\title{
A Smart Collaborative Educational Game with Learning Analytics to Support English Vocabulary Teaching
}

\author{
Ahmed Tlili ${ }^{*}$, Sarra Hattab ${ }^{2}$, Fathi Essalmi ${ }^{3}$, Nian-Shing Chen ${ }^{4}$, Ronghuai Huang ${ }^{1}$, Kinshuk ${ }^{5}$, Maiga \\ Chang $^{6}$, Daniel Burgos ${ }^{7 *}$
}

${ }^{1}$ Smart Learning Institute of Beijing Normal University, Beijing (China)

${ }^{2}$ Higher Institute of Computer Science and Management of Kairouan, Kairouan (Tunisia)

${ }^{3}$ Management Information Systems Department, College of Business, University of Jeddah, Jeddah (Saudi Arabia)

${ }^{4}$ Department of Applied Foreign Languages, National Yunlin University of Science and Technology, 123 University Road, Section 3, Douliou, Yunlin 64002 (Taiwan)

${ }^{5}$ University of North Texas, 3940 N. Elm Street, G 150, Denton, TX, 76207 (USA)

${ }^{6}$ School of Computing and Information Systems, Athabasca University (Canada)

${ }^{7}$ UNIR iTED, Universidad Internacional de La Rioja (UNIR), Logroño (Spain)

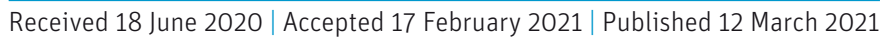

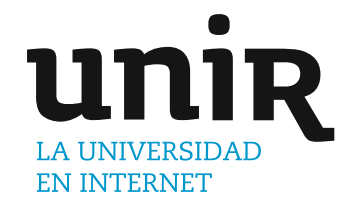

\section{ABSTRACT}

Learning Analytics (LA) approaches have proved to be able to enhance learning process and learning performance. However, little is known about applying these approaches for second language acquisition using educational games. Therefore, this study applied LA approaches to design a smart collaborative educational game, to enhance primary school children learning English vocabularies. Specifically, the game provided dashboards to the teachers about their students in a real-time manner. A pilot experiment was conducted in a public primary school where the students' data from experimental and control groups, namely learning and motivation test scores, interview and observation, were collected and analyzed. The obtained results showed that the experimental group (who used the smart game with LA) had significantly higher motivation and performance for learning English vocabularies than the control group (who used the smart game without LA). The findings of this study can help researchers and practitioners incorporate LA in their educational games to help students enhance language acquisition.

\section{KEYWORDS}

Collaborative Learning, Data Analysis, Educational Games, Language Learning, Learning Analytics.

DOI: $10.9781 /$ ijimai.2021.03.002

\section{INTRODUCTION}

\begin{abstract}
$\Lambda$ RNOLD, Greenville and Doe [1] stated that the traditional Amethods for learning second languages are difficult and less engaged, resulting in negative learning outcomes. Flores [2] stated that Second Language Acquisition (SLA) strategies should be based on technologies since students of this era are technological natives. Additionally, immersive learning experiences play an important role in facilitating SLA. This immersion experience can be achieved by different technologies including games [3]. Several studies have proved that integrating playing and challenge while learning can improve students' outcomes [4]. Consequently, educational games have started gaining an increased attention from researchers and practitioners as a way of engaging students in learning. Educational games are games with the fundamental needs of learning by providing fun, motivation, creativity and social interaction [5], [6]. Especially, while playing
\end{abstract}

* Corresponding author.

E-mail addresses: ahmed.tlili23@yahoo.com(A.Tlili),daniel.burgos@ unir.net (D. Burgos). games, students are situated in a gaming scenario to complete a series of learning tasks individually, collaboratively or even competitively. Despite that educational games are effective tools in enhancing the learning process, several research studies also reported that they are black boxes where teachers cannot unlock what students did in the learning process (except the final scores and levels cleared) and how they behaved towards the learning goal [7], [8].

Therefore, this study describes a smart collaborative educational game developed in this research, based on LA approaches, to teach primary school students English vocabulary. The game collected the students' learning interaction data and analyzed them to create dashboards that can help teachers understand how their students were learning using the game. The teachers can then provide the needed interventions to each student and each team accordingly. Additionally, this game adopted collaborative learning strategy in which achieving the game's goal depends on the efforts of all the team members. While LA approaches have been applied for several educational purposes, little attention has been paid to use these approaches for language acquisition [9], calling for further research in this regard. Additionally, despite that several educational games incorporated LA in the literature, to the best of our knowledge, none of these games applied collaborative learning while playing for second language acquisition. 
Finally, this study compares the impact of the smart collaborative educational game and the non-smart version of the game on students' learning performance and motivation. The only difference between the smart and non-smart versions of the game is that the smart version incorporated LA to provide automatic dashboards about students' learning progress while the non-smart version did not.

The rest of the paper is structured as follows: Section II presents related work related to SLA and learning analytics in educational games. Section III describes the developed fungle animals game- a smart collaborative educational game for teaching English vocabulary. Section IV presents the research method, while Section V presents the obtained results. Finally, Section VI discusses these results with the limitation of this study and future directions.

\section{RELATED WORK}

\section{A. Second Language Acquisition and Collaborative Learning}

Second language acquisition is the learning and acquisition of a second language once the mother tongue or first language acquisition is established [10]. Hart and Risley [11] state that First Language Acquisition (FLA) is different than SLA because FLA occurs naturally and perhaps without any formal instruction, simply by students being constantly exposed to language rich environments over the course of many years. SLA, on the other hand, relies on more specific pedagogical approaches. In these settings, a major goal frequently is to formally teach students the elements of language that are learned much more informally in their native language.

Specifically, this research study aims to collaboratively teach English as a SLA. Collaborative learning is a pedagogical approach that implies students to work in groups to complete an activity or solve a given problem. Siemon, Becker, Eckardt, \& Robra-Bissantz [12] introduce different principles for collaboration systems, as follows: "Reciprocity" refers to exchanging information and efforts. If a collaborator offers more effort, the other members have to return the effort when needed. The "common goal" is the most important factor in collaboration that motivates every team member to work with others. "Mutual respect and trust" enhance teamwork in a variety of ways. It is positively linked to a team performance. "Cohesiveness" refers to the perception of a team as one unified force. "Benevolence and commitment" mean that team members should not intentionally work against their team members and should deliver sufficient efforts to help their teams.

To teach SLA (individually or collaboratively), several researchers have used educational games to motivate students and provide learning environments and scenarios similar to real situations, as discussed in the next section.

\section{B. Educational Games and the Application of Learning Analytics}

Several researchers have highlighted that educational games facilitate language learning since they are interactive and motivating. Additionally, they provide an environment similar to a real one, which enables students to easily practice the needed language and learn it effectively [3]. Surkamp and Viebrock [13] mentioned that games from simple vocabulary to role-playing games could enhance the language learning experience. However, Hung, Chang and Yeh [14] showed in a comprehensive literature review in SSCI language learning journals that only $4 \%$ of the published articles are related to Digital Game Based Language Learning (DGBLL). Additionally, the same authors reported, in their literature review, that $79 \%$ of DGBLL educators prefer to use off-the-shelf digital games over self-developed ones in order to reduce development cost and effort [14]. This shows the need to pay more attention to the development and use of educational games for language learning. Therefore, as a first contribution, this study focuses on developing a collaborative educational game for English vocabulary learning. In this context, Chiu, Kao, and Reynolds [15] highlighted the importance for further research on English learning using games beyond drill and practice genres.

Additionally, despite that educational games, including DGBLL, are motivating and interactive, they are black boxes [7], [8]. This means that teachers will not have the possibility to see how their students are learning (e.g., what they mastered and what not). To change that, researchers have thought of making use of the generated big data from the student's interaction with educational games by analyzing them to understand the learning process. The analysis of learning data is often referred to as LA, which is defined as "the measurement, collection, analysis and reporting of data about students and their context, for purposes of understanding and optimizing learning and the environments in which it occurs" [16]. Hauge et al. [17] mentioned that the provided feedback based on LA can help students do better in an educational game. Reinders [18] further mentioned that LA in language learning can help teachers monitor their students whether there are learning individually or collaboratively, hence provide early interventions and support accordingly. For instance, Youngs, MossHorwitz, and Snyder [19] applied LA for online French learning (not collaborative) and argued that one of the main purposes of LA is to provide teachers insights on student learning and highlight where and when they need to step in to monitor students. Consequently, the students had better learning performances compared to the other group of students (control group). Additionally, several studies showed that analyzing students' online behaviors could help in assessing their language learning performance and obstacles, hence those students who need more learning support could be identified [20], [21].

However, Gelan et al. [22] pointed out that little attention has been paid on the use of LA in language learning. Similarly, Thomas, Reinders and Gelan [9] stated that despite the promise of LA, its application in language teaching and learning has thus far been minimal. Hung, Yang, Hwang, Chu and Wang [23], in their literature review about GBLL, reported that most studies used traditional instruments instead of LA to evaluate the language learning process within games, namely perception questionnaires, learning tests and interviews. Nonetheless, in some studies studying LA in games [24]; [25], no study reported the use of LA in GBLL. This highlights the need for more practical investigations about the potential uses of LA in GBLL. Therefore, this study develops a smart collaborative educational game for teaching English, which incorporates LA to provide learning support for teachers to monitor their students while learning. Table I presents a comparison between various educational games for language learning that were developed in the literature, and the educational game reported in this study (last row of Table I). As the information shown in Table I, it can be seen that a lack of attention has been paid to develop collaborative educational games for English learning with LA support; this is the main contribution of this study.

TABLE I. Comparative Table of Educational Games in the Literature and the Developed Game in This Study

\begin{tabular}{|l|l|l|l|}
\hline Educational game & $\begin{array}{l}\text { Taught } \\
\text { Language }\end{array}$ & Learning type & $\begin{array}{l}\text { Incorporate } \\
\text { learning } \\
\text { analytics }\end{array}$ \\
\hline $\begin{array}{l}\text { Hung, young and } \\
\text { Lin [26] }\end{array}$ & English & Collaboratively & No \\
\hline Hasegawa [27] & English & Individually & Yes \\
\hline $\begin{array}{l}\text { Wichadee and } \\
\text { Pattanapichet [28] }\end{array}$ & English & Individually & Yes \\
\hline Gamlo [29] & English & Individually & No \\
\hline Bahari [30] & English & Collaboratively & No \\
\hline Jungle animals & English & Collaboratively & Yes \\
\hline
\end{tabular}


To summarize, this study contributes to extend the literature by developing a smart collaborative educational game, namely "Jungle animals game" for teaching English to primary school students. This game applied different collaborative strategies to enhance learning English vocabulary. It also incorporated LA approach based on K-mean algorithm to generate automatic dashboards for teachers to monitor their students and provide real-time interventions for them, as well as for students to keep track of their learning progress. K-means was chosen because of the simple implementation, speed of convergence and adaptability to sparse data [31].

\section{JUNGle ANimAls GAME}

\section{A. Collaborative Learning}

Jungle animals is an adventure 2D - multiplayer game that aims to teach English vocabulary, specifically animal names, as well as the spelling of each word for primary school students. The motivation behind choosing this topic (animal names) is that, most students are already familiar with the names of animals in their native language. Additionally, animals are a popular topic in early English curriculums [32]. In a face-to-face game setting, each student can see the other team members to ensure the individual accountability and increase collaboration. The story of the game is that a plane fell into an unknown forest. The survivors (students) must work together to find a computer with the GPS in it to escape. In the first level, the students have to find the password so they can use the computer. To do so, they have to collect letters and sounds which will be used for the password. During the second level, the students navigate to the nearest city where they will meet an old man to get instructions on how to make a city map by collecting pictures and words in the city, so they can find the right way to the airport to go home.

The students can be in different locations or in a shared area (forest in the proposed game) to increase interaction and collaboration among them [33]. Specifically, the shared "objects", such as letters, sounds and animals, can be found by different team members and they have then to exchange acquired information through social interaction. For instance, as shown in Fig. 1, a student in the first level cannot find the password without his/her team members' help because letters and sounds are divided among them. Therefore, they have to communicate via the chat box and work together to insert the password. Table II presents the different mechanisms used in the developed educational game in this study and how they promote collaboration.

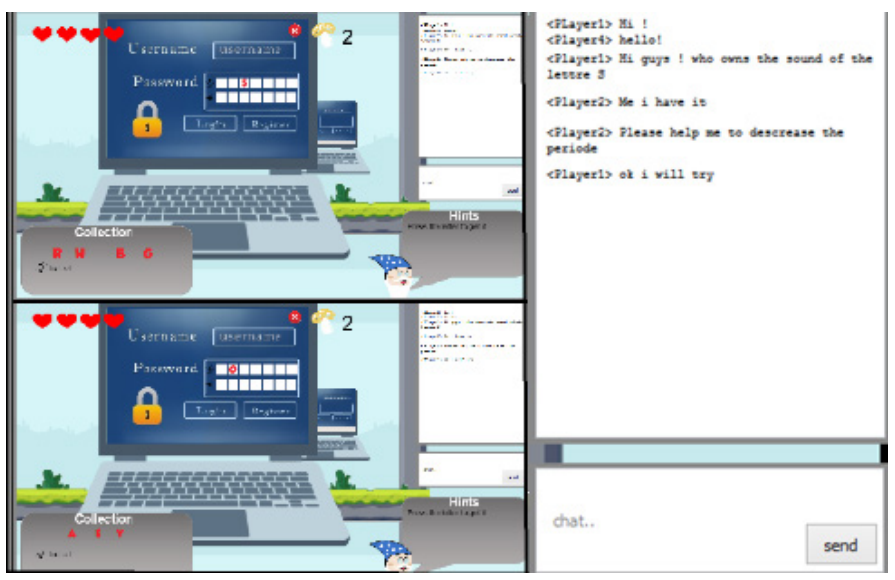

Fig. 1. An example of "insert password" collaborative task using chat box.

Furthermore, the game applies the receptive vocabulary knowledge based on the Nation's taxonomy [34]. It also supports the main parts of receptive knowledge of words, namely form and meaning. The receptive knowledge of word involves being able to recognize the form of the word when it is heard or met while reading. At the beginning of the game, different animal names are presented with their pictures. Students cannot move before hearing each word and seeing its spelling. The game also includes activities that allow students to exercise the spelling of the word in the second level, as shown in Fig. 2. For example, to collect pictures of animals, they have to work together to complete the missing letters.

TABLE II. The Implemented Collaborative Mechanisms in the Game

\begin{tabular}{|c|c|c|c|}
\hline \multirow{2}{*}{$\begin{array}{l}\text { Principles of } \\
\text { collaboration }\end{array}$} & \multirow{2}{*}{ Game mechanisms } & \multicolumn{2}{|c|}{ Jungle animals Game } \\
\hline & & Level 1 & Level 2 \\
\hline Reciprocity & $\begin{array}{l}\text { - Collaborative task } \\
\text { - Encrypted information }\end{array}$ & $\begin{array}{l}\text { Members do the same effort/activities: } \\
\text { - Each one is responsible on a part of the word and } \\
\text { must put it in the correct place. } \\
\text { - Each student has parts of the password (letters } \\
\text { or sounds). A student cannot put the password } \\
\text { without the help of his/her group. } \\
\text { Exchanging information: } \\
\text { - Each student has a unique information and he/ } \\
\text { she must share it with his/her team members to } \\
\text { find the password. } \\
\text { - The students can use the chat box to share } \\
\text { information and communicate together. }\end{array}$ & $\begin{array}{l}\text { Members have the same effort/activities: } \\
\text { - To collect the animal pictures, each student must } \\
\text { write the missing letters. } \\
\text { - To collect part of the words, the students must } \\
\text { complete the missing parts. } \\
\text { Exchanging information: } \\
\text { - The students can exchange information through } \\
\text { the chat box. }\end{array}$ \\
\hline Common goal & Collaborative task & $\begin{array}{l}\text { Find the password using indices and write it with } \\
\text { letters and sounds that are collected together. }\end{array}$ & $\begin{array}{l}\text { Connect each animal with its name to complete the } \\
\text { city map with the collected parts and pictures. }\end{array}$ \\
\hline Cohesiveness & $\begin{array}{l}\text { - Shared space } \\
\text { - Shared object }\end{array}$ & Shared interface, shared letters, shared sounds. & Shared interface, shared pictures, shared words. \\
\hline $\begin{array}{l}\text { Benevolence and } \\
\text { commitment }\end{array}$ & $\begin{array}{l}\text { - Shared space } \\
\text { - Shared object }\end{array}$ & $\begin{array}{l}\text { Ensuring the cohesiveness enhances individual } \\
\text { benevolence and commitment. }\end{array}$ & $\begin{array}{l}\text { Ensuring the cohesiveness enhances individual } \\
\text { Benevolence and commitment. }\end{array}$ \\
\hline
\end{tabular}




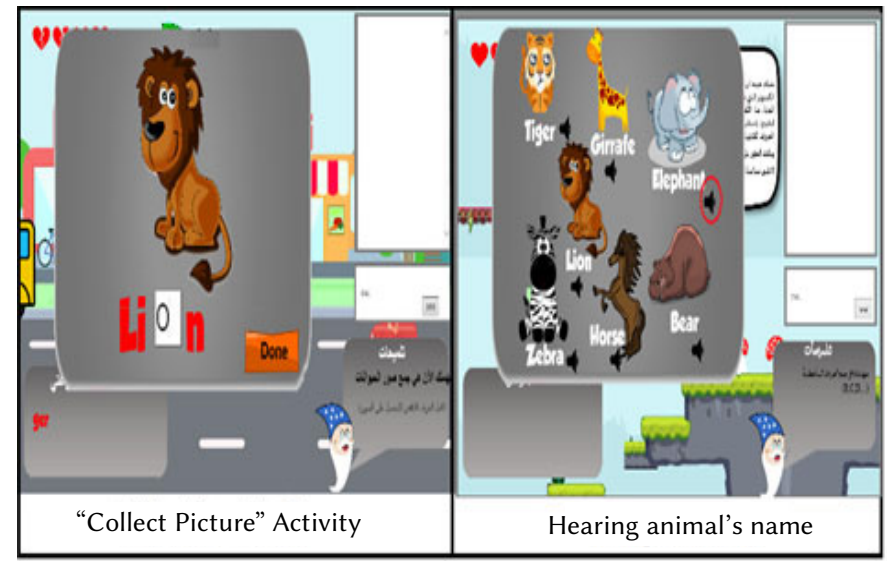

Fig. 2. Learning the form of words by filling the missing letters.

In addition, recognizing different portions of the word are also very important in the form part. Therefore, the game provides activities that develop recognizing portions of the words. Specifically, each student has a portion of the word, and they must collaborate together to combine all the pieces together before they can move to the next level. Regarding the meaning part, the knowledge of a word involves knowing its meaning. Therefore, the game adopts repetition and memory pedagogical strategy, proposed by Schmitt \& McCarthy [35], to elicit word meaning. Memory strategy refers to relating the word with student's knowledge using images. In this context, students will encounter the same words and pictures in a repetitive cycle during different times at several activities.

The smart collaborative educational game aims to provide learning materials in a collaborative and fun way using tight coupling between text, speech and images to make the students learn how to pronounce each name and remember it when they see the picture of an animal. From the pedagogical perspective, it is difficult for teachers to keep up with each group and see how each student is behaving with his/her team members, as well as individual student's learning obstacles when it comes to learning the names of animals. For instance, a student might remember the outlook of an animal, but he/she still cannot spell the correct name of the animal. Also, a student might still have problems with memorizing the names of some animals. All these kinds of questions can be easily solved by providing dashboards to teachers and students through learning analytics (LA) approach.

\section{B. Design of Learning Analytics}

Link and Li [36] highlighted several language learning interaction data that should be collected for LA based different theoretical approaches (e.g., interactionist, complexity, etc.). This study has relied specifically on "Skill acquisition theory" and "Interactionist theory", thus it analyzed performance data and communication activity data respectively (see Table III). Specifically, these traces can help teachers discover students' learning obstacles from three aspects, the individual aspect (the learning performance of each student), the group aspect (the learning performance of each group and the collaboration patterns among the members of each group) and the class aspect (the learning performance of the whole classroom. Consequently, each teacher will have the detailed information about how students learn from these three different aspects (individual, group and class).

During the process of game playing, time spent in different learning activities, wrong answers and retrying times were collected for each student and each group. The group communication patterns were also collected in order to evaluate the collaborative process during the game. Finally, the collected traces were automatically saved in an online database using PHP scripts. It should be noted that the smart collaborative educational game supports hundreds of students and vocabularies (animal names), and the limited number of students during this pilot experiment (see the next section) does not affect the technical reliability of the developed game.

TABLE III. The Collected LeArning Traces

\begin{tabular}{|c|c|}
\hline Learning traces & Description \\
\hline Time of solving activities & $\begin{array}{l}\text { The total time that the student spends in } \\
\text { each activity. }\end{array}$ \\
\hline Number of wrong answers & $\begin{array}{l}\text { Number of wrong answers made by the } \\
\text { student before he/she finds the correct one } \\
\text { during each activity. }\end{array}$ \\
\hline Difficult activities & $\begin{array}{l}\text { Activities that the student did not answer } \\
\text { during the game. In addition, activities that } \\
\text { student did not come out a solution until } \\
\text { the game provides hints or answers. }\end{array}$ \\
\hline Group time & $\begin{array}{l}\text { The total time a group spent on achieving } \\
\text { the common goal. }\end{array}$ \\
\hline Group wrong answers & $\begin{array}{l}\text { Number of wrong answers made by group } \\
\text { members until they achieve the common } \\
\text { goal of the activity. }\end{array}$ \\
\hline Group communication & $\begin{array}{l}\text { The number of discussing messages among } \\
\text { the group members in the chat box. }\end{array}$ \\
\hline
\end{tabular}

After collecting learning data, data mining and visualization techniques were applied to provide a detailed learning dashboard for teachers, to help teachers monitor their class and provide the needed interventions for each group or student accordingly. Gross, Stary and Totter [37] recommended that visualization tools for online learning should provide both group awareness and individual objective selfawareness. Group awareness presents information about group activities, collaborations and status [38], while individual objective self-awareness presents information on the process of taking oneself as the focus of one's behaviors and achievements [39].

An automatic game dashboard was created to display the current achievements of each individual student and group at any point of time. This dashboard shows how the students are progressing in the game. Specifically, it shows the number of completed activities by the students, as well as the number of correct and wrong answers (see Fig. 3). For example, most of the students did not answer correctly in the first learning activity (the yellow portion) as shown in Fig. 3, therefore the teacher should not move to the second learning activity, instead the teacher should help students answer the first learning activity by providing more explanation on the classroom blackboard. Additionally, the game dashboard shows the number of wrong answers given in each learning activity and the time spent in this activity. These features can provide teachers to have a global view about the learning difficulties of their students and help them accordingly. Similarly, the students can also access to the dashboards from their "student interface" to understand their learning performance and problems. For instance, students can see their own learning weakness and try to overcome it.

Furthermore, based on the group communication log data from the chat box of the game, the dashboard presents the interaction frequency in each group while collaborating. The communication frequency is also presented for each student while collaboratively solving different learning activities. Consequently, teachers can know if a group is experiencing certain collaboration problems and can check on them to provide needed help. Teachers can also know the communication frequency of each student during a specific period (e.g., the first level of the game) or during a specific activity (e.g., while solving the first learning activity), and understand how each student is involving in the learning process (as active or passive actor). 
Activity Time (Seconds)
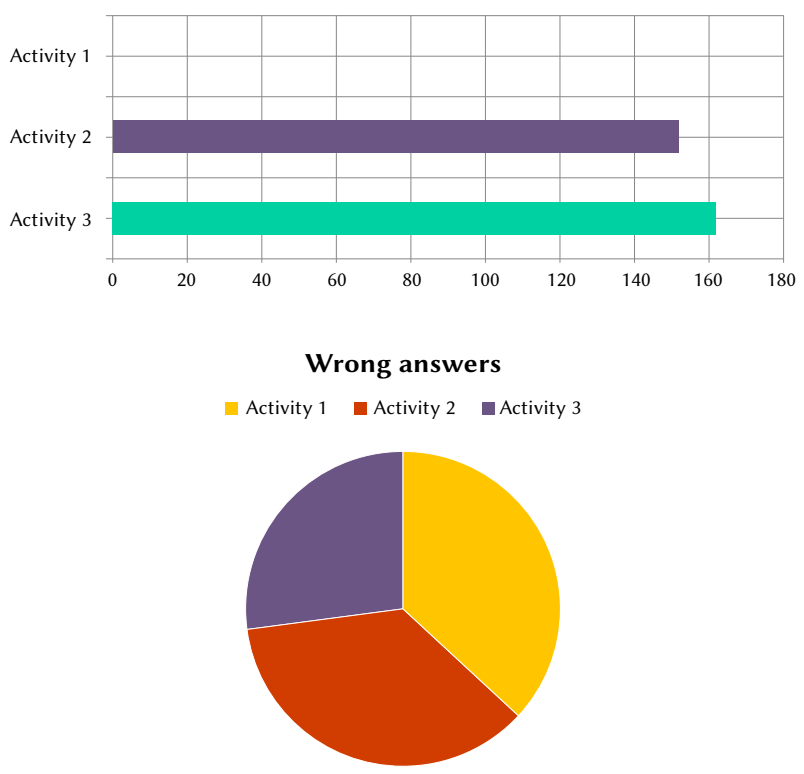

Fig. 3. Examples of learning dashboards generated by the smart collaborative educational game.

Finally, the dashboard automatically generates student clustering using K-means algorithm based on those with high, medium and low performance (see Fig. 4). This information can help teachers to provide required interventions to students according to different learning performance. The K-means algorithm divides the objects into $\mathrm{k}$ clusters, and iterates through the division-process as long as the distance between all objects and the center or mean of the clusters can be reduced. A characteristic of this algorithm is that the number $\mathrm{k}$ of clusters has to be fixed. In the game, the $\mathrm{K}$ value is fixed to 3 (similar to the above three groups) and two student features are used as inputs, namely number of wrong answers and time solving the activities. Fig. 4 shows the graphic representation of the three clusters with respect to the means of the two features. Since the first cluster has the highest mean of wrong answers and of time spent on activities, it is labeled "low performance". The second cluster is "high performance" and the final cluster is "medium performance".

\begin{tabular}{|l|l|l|}
\hline Name & Wrong answers & Time (Seconds) \\
\hline $\mathrm{Mo}$ & 21 & 123 \\
\hline $\mathrm{Ha}$ & 9 & 177 \\
\hline $\mathrm{Am}$ & 15 & 60 \\
\hline $\mathrm{Sa}$ & 12 & 102 \\
\hline $\mathrm{No}$ & 12 & 120 \\
\hline $\mathrm{Ra}$ & 12 & 132 \\
\hline $\mathrm{Do}$ & 15 & 123 \\
\hline
\end{tabular}

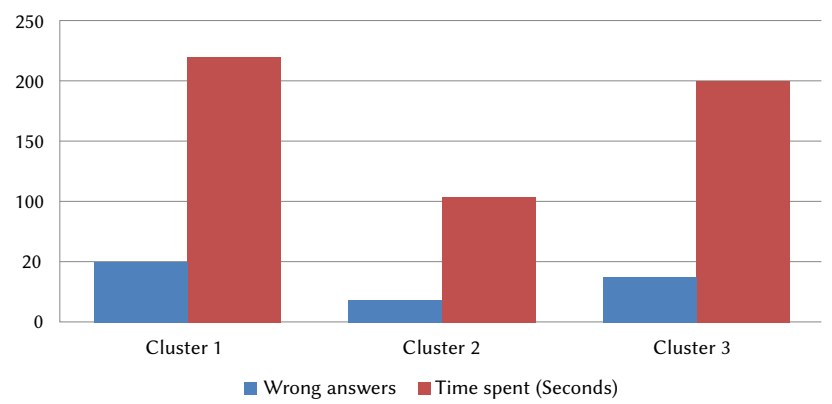

Fig. 4. Examples of the generated clusters using K-means algorithm by the smart collaborative educational game.
IV. METHOD

Unlike educational games that incorporate LA, educational games without LA are black boxes and teachers cannot see how the learning process is occurring. Hence, they cannot provide real-time learning support to help students achieve better learning outcomes. Additionally, students cannot receive any instant feedback about their learning progress and performance. Based on this, this study aimed to validate the following two hypotheses.

H1: Students learning with the developed smart collaborative educational game (with LA) have significantly higher learning performance than students learning with the non-smart version of the game (without LA).

H2: Students learning with the developed smart collaborative educational game have (with LA) significantly higher learning motivation during the learning process than students learning with the non-smart version of the game (without LA).

\section{A. Participants}

A pilot experiment, during the academic year 2018-2019, was conducted to validate the two hypotheses at a public primary school after receiving the approval from school review board (including parents' consent forms). Thirty-one sixth-grade primary school students participated in this study where $70 \%$ of them were boys and $30 \%$ were girls. The average age of the students was 12 years old. The students were randomly divided into two groups, namely experimental and control groups.

\section{B. Experimental Procedure}

The teacher started by introducing the game to the students in both groups (fifteen minutes for each group). After that, the students in each group (experimental and control) took forty-five minutes to answer a pre-test and a pre-motivation questionnaire to assess their prior-knowledge and motivation related to English vocabulary. The students in the experimental group then used the smart collaborative educational game (with LA) to learn English, while the students in the control group used the non-smart version of the educational game (without LA). The learning process of both groups was in different time slots (morning and afternoon) in order for the same teacher to facilitate both learning processes. The learning process was for three hours for each group (control and experimental). The game included twenty animal names, where ten of them are herbivore and the other ten are carnivore. The students were divided into different teams with four members in each team; two members with high English vocabulary achievements and two members with low English vocabulary achievements (based on their English test results from the previous academic year). Finally, after the learning process was ended, the students in both groups completed a post-test and a postmotivation questionnaire.

\section{Instruments and Data Collection}

Both qualitative and quantitative data from both the students and the teacher are collected using the following three instruments. The main idea is that the results from qualitative analysis should further support and explain the quantitative results.

- Pre and post-test: It was designed by experienced teachers who had taught English courses in primary school for the past fifteen years. This test contains three different items and aims to measure each student's learning performance regarding animal names learned during the game. For instance, in the first item, students were requested to fill the missing letters of a particular given name of an animal. In another item, students were requested to link using arrows the animal picture with its correct name, among several 
provided names. The students took between 25 and 30 minutes to finish this test. It should be noted that the pre and post-tests are the same and 10 is the highest grade that a student can obtain.

- Preandpost-motivation questionnaire:The motivation questionnaire was adapted from Wigfield and Guthrie [40]. It aims to measure the motivation level of students during the learning process using the game. It consists of nine items on a four-point scale (1 strongly disagree; 2 disagree; 3 agree; and, 4 strongly agree). The Cronbach's alpha of the questionnaire was calculated and it was equal to 0.83. This implied that it was reliable since Cronbach's alpha value was greater than 0.7 [41]. It should be noted that the pre and post-motivation questionnaires are the same.

- Interview: A semi structured interview was conducted with the teacher to collect his feedback about using the smart collaborative educational game and the non-smart version of it for teaching English vocabulary. The interview took 30 minutes and it was recorded in order to be analyzed and draw conclusions. The coding process was done by two coders, and in case of disagreement, the two researchers resolved it through discussion. Specifically, four codes were used for the qualitative analysis of interviews, namely: (1) Learning obstacle: Use this code when the teacher is talking about how using the smart and non-smart versions of the educational game helped him in identifying the learning obstacle (difficulties, wrong answers, etc.) of students; (2) Timely intervention: Use this code when the teacher is talking about how using the smart and non-smart versions of the educational game helped him in providing immediate or effective learning interventions; (3) Communication: Use this code when the teacher is talking about communication and interaction between students while using the smart and non-smart versions of the educational game; and, (4) Reflection: Use this code when the teacher is talking about students' self-reflection while using the smart and nonsmart versions of the educational game.

- Observation: During the learning processes (using the smart collaborative educational game and the non-smart version of it), two observers were in the classrooms to observe the effects of the two games on the learning behaviors of students. The two chosen observers are teachers with more than twenty years teaching experience, and they did not have any previous relationship with the students. The coding process was done by two coders (same coders who coded the interview), and in case of disagreement, the two coders resolved it through discussion. Specifically, the coders mainly focused on two aspects which can affect the learning motivation, namely interactivity [37], [38] and exhibiting excitement and fun [39]. Specifically, two codes were used for the qualitative analysis of observations, namely: (1) Interaction: Use this code for all occurrences that illustrate teacher-student, studentstudent or student-game interactions while using the smart and non-smart version of the collaborative educational game; and, (2) Excitement/Fun: Use this code for all occurrences that illustrate students are exhibiting excitement or fun while using the smart and non-smart version of the collaborative educational game.

\section{Results}

\section{A. Impacts on Learning Performance (Hypothesis 1)}

The pre-test scores of both groups (control and experimental) were analyzed using the two sample t-test which was reported as an effective statistical method to deal with limited sample size [40], as shown in Table IV. The obtained results showed that there was no significant difference in the pre-test performance of both groups since the $\mathrm{p}$ value was equal to .066 and greater than .005 . To conclude, there was no significant difference in the prior-knowledge of English vocabulary between the control and experimental groups before the beginning of the learning process.

TABLE IV. Two-sample T-test Results of the Pre-tests Analysis

\begin{tabular}{llllll}
\hline Pair 1 & Mean & SD & t & df & Sig \\
Pre_testl \& Pre_test2 & 1.6 & .66 & -3.1 & 14 & .066 \\
\hline
\end{tabular}

After the learning process, the post-test scores were analyzed using the two-sample t-test, as shown in Table V. The obtained results showed that there was a significant difference in the post-test performance of both groups since the $\mathrm{p}$ value was equal to .001 and less than .05. Specifically, the experimental group achieved higher scores in the post-tests of English vocabulary than the control group.

TABLE V. Two-sample T-test Results of the Post-tests Analysis

\begin{tabular}{llllll}
\hline Pair 2 & Mean & SD & t & df & Sig \\
Post_test1 \& Post_test2 & 6.22 & 3.25 & 4.37 & 14 & .001 \\
\hline
\end{tabular}

To understand how the smart collaborative educational game helped the experimental group achieving a better learning performance, the teacher was interviewed and the given answers were qualitatively analyzed. The distribution rate of each coding item is presented in Fig. 5. Specifically, it can be seen from these bar chart that the smart collaborative educational game was more helpful for the teacher than the non-smart version of it. To better understand the obtained results of each coding distribution, the interview answers were analyzed and discussed as follows:

- Learning weakness: The teacher reported that the provided dashboards in the smart version of the educational game helped him to identify the learning weakness of the students (individually or in groups). However, this was not very easy when he used the non-smart version of the game since he had to go through every team and keep an eye on their computer screens to see how they are performing, as no feedback was given to him (i.e., the game was a black box). For instance, the teacher mentioned that, from the provided LA dashboard, he could easily see that some students still cannot spell correctly "giraffe" and "elephant". He also mentioned that the smart collaborative educational game helped him automatically identify students with different learning performances (low, medium and high). For instance, the teacher mentioned that he can easily see that the student $<$ name withheld $>$ was struggling to solve the first activity compared to his team members.

- Communication: The teacher mentioned that both educational games (the smart and the non-smart version of it) enhanced the communication level between the students as they both support the collaborative learning strategy. This was further reflected in the "communication" bar chart in Fig. 5, as no huge difference was seen. However, the teacher mentioned that the provide LA dashboards within the smart collaborative educational game made the students more interactive compared to the students who used the non-smart version of it. For instance, every time the students see their team performance, through the LA dashboards, compared to the other teams, they start discussing their learningplaying strategies to increase their winning chances. The teacher further mentioned that the students sometimes leave their seats and go to their peers to talk to them, instead of using the chat box. This was encouraging and helpful in a way that the students were motivated to learn from each other. 
- Timely intervention: As discussed in the first coding scheme, unlike the non-smart version of the educational game, the smart educational game provided detailed information using dashboards to the teacher about the learning weakness of his students. Therefore, he provided timely interventions accordingly. For instance, when he noticed that some students still cannot spell correctly "giraffe" and "elephant", he helped them write it down on the board couple of times to memorize it. Also, he instantly provided help to the student $<$ name withheld $>$ in order to correctly finish the first activity. Furthermore, the teacher mentioned that every time he sees that the communication frequency of some groups is low, he goes there to encourage them to communicate together. Finally, the teacher mentioned that the provided dashboards helped him assess his class performance and identify their weakness, hence easily identify the supplemental learning materials that he needed to suggest.

- Reflection: The teacher mentioned that both educational games (the smart and the non-smart version of it) through the collaborative strategy helped students to have self-reflection about their actions and achievements while communicating with their team members via the chat box about their learning-playing strategies to win. The teacher, however, mentioned that the LA dashboards specifically, within the smart collaborative educational game, further emphasized self-reflection by summarizing the learning progress of each student in simple dashboards. Consequently, it is seen that several students refer to the dashboard to see their learning weakness and then start consulting their peers via the chat box for help.

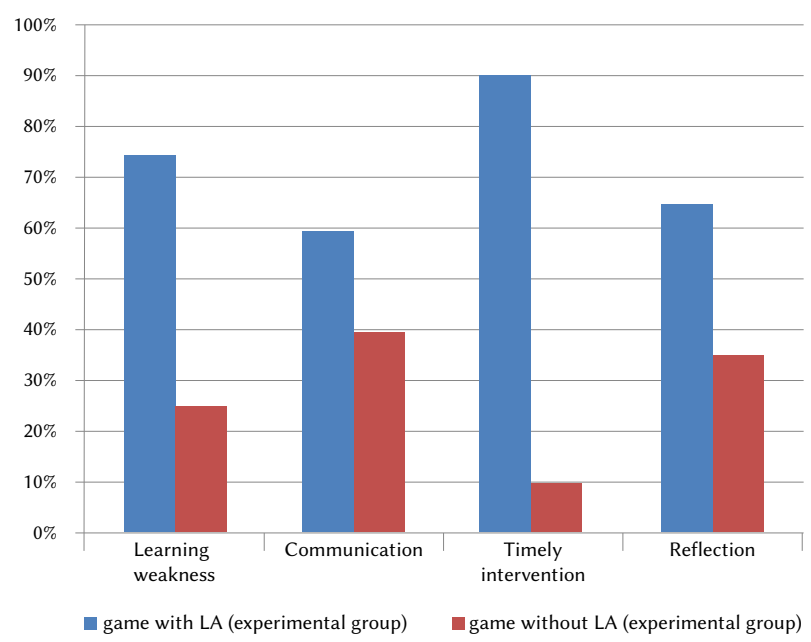

Fig. 5. Distribution of the four interview features based on the used version of the game.

\section{B. Impacts on Motivation Level (Hypothesis 2)}

Similar to the first analysis, the pre-motivation questionnaire scores of both groups were analyzed using two sample t-test as shown in Table VI. The obtained results showed no significant difference in the motivation levels between the experimental and control groups towards learning English vocabulary before the experiment. Particularly, the p value was equal to .41 and greater than .05 .

TABLE VI. Two-sample T-test Results of the Pre-motivation Questionnaire Analysis

\begin{tabular}{lccccc}
\hline Pair 1 & Mean & SD & t & df & Sig \\
Pre_quest1 \& Pre_quest2 & 1.21 & .77 & -4.72 & 13 & .41 \\
\hline
\end{tabular}

After the learning process, the post-motivation questionnaire scores were analyzed as well using the two-sample t-test, as shown in Table VII. The obtained results showed that there was a significant difference in the post-motivation questionnaire scores of the two groups since the $\mathrm{p}$ value was equal to .01 and less than .05 . Specifically, the experimental group had a higher motivation level towards learning English vocabulary than the control group.

TABLE VII. Two-sample T-test Results of the Post-motivation QUESTIONNAIRE ANALYSIS

\begin{tabular}{llllll}
\hline Pair 2 & Mean & SD & t & df & Sig \\
Post_quest1 \& Post_quest2 & 3.81 & 1.81 & $-2,14$ & 13 & .01 \\
\hline
\end{tabular}

To understand how the smart collaborative educational game helped the experimental group achieving a higher motivation level, the observations of both learning processes (using the smart collaborative educational game and the non-smart version of it) were qualitatively analyzed. The distribution rate of each coding item is presented in Fig. 6. Specifically, it can be seen from these bar chart that the smart collaborative educational game made students more interactive and exhibit high level of fun and excitement than the students who used the non-smart version of it. Consequently, these students had higher motivation level. To better understand the obtained results of each coding distribution, the collected observations were analyzed and discussed as follows:

- Interaction: It is evidenced that the LA dashboard provided by the smart collaborative educational game made the students very active and engaged. This is seen when they always refer to this dashboard to start discussing strategies to win or helping each other to increase their chances of winning. This created a motivating atmosphere while learning. When using the nonsmart version of the game, interaction was relatively low among students due to the absence of dashboards, where they discussed only the learning-playing process. However, it was seen that some students asked directly their friends about their performance and some learning conversation happened as a result.

- Excitement/Fun: It is evidenced that the provided learning dashboards by the smart collaborative educational game made the students very excited. Specifically, it was frequently seen that the students in each team expressed excitement when they referred to the dashboards and saw that they are wining and. However, this was not the case in the non-smart version of the game. Particularly, the students expressed high excitement level only at the beginning of the learning process (during the first 15 or 20 minutes) since using the game was fun for them.

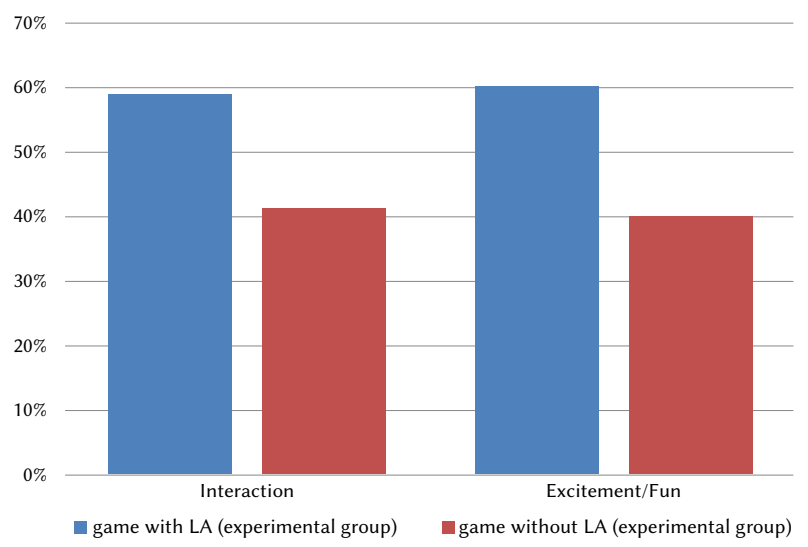

Fig. 6. Distribution of the two observation features based on the used version of the game. 
VI. Conclusions, Discussions AND IMPliCATIONS

This study developed and validated a smart collaborative educational game incorporated with LA to teach English vocabulary. The first obtained results showed that the students who learned English vocabulary using the smart collaborative educational game achieved a higher learning performance than students who used the non-smart version of the game. This can be explained by the automatically generated dashboards by the smart collaborative educational game for teachers to get real-time information about their students' learning situations and provide the needed interventions in a timely manner. From the pedagogical perspective, Reinders [18] found that LA can help teachers monitor their students whether they are learning individually or collaboratively, hence provide early interventions and support accordingly. Additionally, the teacher during the conducted interview revealed that displaying team achievements using LA dashboards to the students could also help them perform better. In this context, several researchers mentioned that providing learning achievements information of individuals and groups in collaborative environments could enhance online participation and learning performances [37].

The second obtained results showed that students who used the smart collaborative educational game had a higher motivation level than the students who used the non-smart version of the educational game. This could be attributed to the smart collaborative educational game can facilitate self-reflection via the provided dashboards (as reported in the interview results), this has affected positively the students' learning motivation and outcomes. In this context, several research studies showed that supporting self-reflection can enhance students' learning motivation [46], [47]. Particularly, the information displayed on the dashboard provided by the smart collaborative educational game to the students about their learning progress made them more excited and encouraged them to do better, hence they were very motivated. In this context, Wang [48] stated that an educational game can motivate students while learning, but their motivation level will start decreasing once they get familiar with the game. Therefore, incorporating motivational strategies to encourage continuous play is crucial [49]. An effective motivational technique in education is to highlight a student's accomplishments [50], thus LA dashboards that visualize a student's improvement could be motivating. Additionally, it had seen that the smart collaborative educational game, through the provided dashboards made the students more interactive by collaborating together to win than the students who used the nonsmart version of the game. Similarly, several studies also showed that providing interactive learning process can positively affect the students' learning motivation [42]; [43].

The findings of this research could enhance the educational technology field by presenting a new learning tool (smart collaborative educational game) that can collaboratively help in learning English vocabulary. Specifically, this study presented examples of implementing game mechanics and scenarios that other researchers and practitioners could apply in their respective educational game contexts to fulfill different collaborative learning strategies. For instance, to fulfill memory strategy, students will encounter, during the game, the same words and pictures in a repetitive cycle during different times at several activities. This will elicit their memory and help them recall the learned knowledge. Some suggestions to the designers and teachers learned from this study are: (1) focus not only on the learning perspective (performance, weakness and progress), but also on the social perspective as well (communication between peers/teachers); (2) provide feedback during the learning process about both individual and team achievements; and, (3) provide simple interfaces (dashboards) without detailed information (using pie chart, histograms, etc.) to help teachers/students easily identify important information and make use of it.
It should be noted that this study has several limitations that should be acknowledged and further investigated. For instance, the sample size of the experiment was limited, due to the experiment context (public school). Also, the learning process of each group (control and experimental) was only for three hours. However, despite these limitations, this study presented insights, including practical examples and recommendations for applying both collaborative learning as well as learning analytics in DGBLL. Future research work could focus on making the designed game smarter by providing automatic learning support and interventions based on different learning scenarios and conditions. For instance, when a team is having low communication frequency, the game will start providing encouragements for students to make them more active and share ideas together. In addition, future directions could focus on designing a mobile version of this game, as language learning games are gaining an increasing attention on mobile devices [51].

REFERENCES

[1] M. Arnold, S. C. Greenville, \& R. Doe, "Second Language Acquisition Video Game." Accessed: Oct. 15, 2019. [Online]. Available: https://cse. sc.edu/files/Matthew\%20and\%20Renaldo.pdf.

[2] J. F. F. Flores, "Using gamification to enhance second language learning," In Digital Education Review, vol. 27, no. 21, pp. 32-54, 2015.

[3] M. Amoia, T. Brétaudière, A. Denis, C. Gardent, \& L. Perez-Beltrachini, "A serious game for second language acquisition in a virtual environment," fournal on Systemics, Cybernetics and Informatics (FSCI), International Institute of Informatics and Systemics, vol. 10, no. 1, pp. 24-34, 2012.

[4] C. Y. Hung, J. C. Y. Sun, \& P. T. Yu, "The benefits of a challenge: student motivation and flow experience in tablet-PC-game-based learning." Interactive Learning Environments, vol. 23, no. 2, pp. 172-190, 2015, doi: 10.1080/10494820.2014.997248.

[5] M. Filsecker, \& D. T. Hickey, "A multilevel analysis of the effects of external rewards on elementary students' motivation, engagement and learning in an educational game," Computers \& Education, vol. 75, pp. 136-148, 2014, doi: 10.1016/j.compedu.2014.02.008.

[6] A. Hawlitschek, \& S. Joeckel, S. "Increasing the effectiveness of digital educational games: The effects of a learning instruction on students' learning, motivation and cognitive load," Computers in Human Behavior, vol. 72, pp. 79-86, 2017, doi: 10.1016/j.chb.2017.01.040.

[7] C. Alonso-Fernandez, A. Calvo, M. Freire, I. Martinez-Ortiz, \& B. Fernandez-Manjon, "Systematizing game learning analytics for serious games," in 2017 IEEE Global Engineering Education Conference (EDUCON), Athens, Greece, 2017, pp. 1111-1118.

[8] A. Tlili, \& M. Chang, M. "Data Analytics Approaches in Educational Games and Gamification Systems: Summary, Challenges, and Future Insights," in Data Analytics Approaches in Educational Games and Gamification Systems, Springer, Singapore, 2019, pp. 249-255.

[9] M. Thomas, H. Reinders, \& A. Gelan, "Learning analytics in online language learning: Challenges and future directions." in Faces of English Education, Oxfordshire, England, UK, Routledge, 2017, pp. 197-21.

[10] D. Matukhin, \& D. Bolgova, "Learner-centered Approach in Teaching Foreign Language: Psychological and Pedagogical Conditions," ProcediaSocial and Behavioral Sciences, vol. 206, pp.148-155, 2015.

[11] B. Hart, \& T. R. Risley, Meaningful differences in the everyday experience of young American children, Paul H Brookes Publishing, 1995.

[12] D. Siemon, F. Becker, L. Eckardt, \& S. Robra-Bissantz, "One for all and all for one-towards a framework for collaboration support systems," Education and Information Technologies, vol. 24, no. 2, pp. 1837-1861, 2019, doi: 10.1007/s10639-017-9651-9.

[13] C. Surkamp, \& B. Viebrock, B., Teaching English as a Foreign Language: An Introduction, Stuttgart, Germany: JB Metzler: Springer, 2018.

[14] H. T. Hung, J. L. Chang, \& H. C. Yeh, "A review of trends in digital gamebased language learning research," in 16th International Conference on Advanced Learning Technologies (ICALT), Austin, TX, United States, 2016, pp. 508-512.

[15] Y. H. Chiu, C. W. Kao, \& B. L. Reynolds, "The relative effectiveness of digital game-based learning types in English as a foreign language 
setting: A meta-analysis," British fournal of Educational Technology, vol. 43, no. 4, pp. 104-107, 2012.

[16] G. Siemens, \& P. Long, "Penetrating the fog: Analytics in learning and education," EDUCAUSE review, vol. 46, no. 5, p. 30, 2011.

[17] J. B. Hauge, R. Berta, G. Fiucci, B. F. Manjón, C. Padrón-Nápoles, W. Westra, \& R. Nadolski, "Implications of learning analytics for serious game design,"in 14th international conference on advanced learning technologies, Athens, Greece, 2014, pp. 230-232.

[18] H. Reinders, "Learning Analytics for Language Learning and Teaching." JALT CALL fournal, vol. 14, no. 1, pp.77-86, 2018.

[19] B. Youngs, S. Moss-Horwitz, \& E. Synder, "Educational data mining for elementary French on-line: A descriptive study," in E. Dixon \& M. Thomas (Eds.), Researching language learner interactions online: From social media to MOOCs, Texas: CALICO, 2015, pp. 347-368.

[20] E. Martín-Monje, M. D. Castrillo, \& J. Mañana-Rodríguez, "Understanding online interaction in language MOOCs through learning analytics," Computer Assisted Language Learning, vol. 31, no. 3, pp. 251-272, 2018.

[21] F. Rubio, J. M. Thomas, \& Q. Li, "The role of teaching presence and student participation in Spanish blended courses. Computer Assisted Language Learning, vol. 31, no. 3, pp. 226-250, 2018.

[22] A. Gelan, G. Fastré, M. Verjans, N. Martin, G. Janssenswillen, M. Creemers,., ... \& M. Thomas, "Affordances and limitations of learning analytics for computer-assisted language learning: a case study of the VITAL project," Computer Assisted Language Learning, vol. 31, no. 3, pp. 294-319, 2018.

[23] H. T. Hung, J. C. Yang, G. J. Hwang, H. C. Chu, \& C. C. Wang, "A scoping review of research on digital game-based language learning," Computers \& Education, vol. 126, pp. 89-104, 2018, doi: 10.1016/j.compedu.2018.07.001.

[24] C. Alonso-Fernández, A. Calvo-Morata, M. Freire, I. Martínez-Ortiz, \& B. Fernández-Manjón, "Applications of data science to game learning analytics data: A systematic literature review," Computers \& Education, vol. 141, 2019, doi: 10.1016/j.compedu.2019.103612.

[25] M. Freire, Á. Serrano-Laguna, B. Manero, I. Martínez-Ortiz, P. MorenoGer, \& B. Fernández-Manjón, "Game learning analytics: learning analytics for serious games," Learning, design, and technology Springer Nature Switzerland AG, pp. 1-29, 2016, doi: 10.1007/978-3-319-17727-4_21-1

[26] H. C., Hung, S. S. C., Young, \& C. P., Lin, "No student left behind: a collaborative and competitive game-based learning environment to reduce the achievement gap of EFL students in Taiwan." Technology, Pedagogy and Education, vol. 24, no. 1, pp. 35-49, 2015, doi: 10.1080/1475939X.2013.822412.

[27] Hasegawa, et al., "An English vocabulary learning support system for the learner's sustainable motivation," Springer Plus, 2015, doi: 10.1186/ s40064-015-0792-2.

[28] S., Wichadee, \& F., Pattanapichet, "Enhancement of performance and motivation through application of digital games in an English language class," Teaching English with Technology, vol.18, no.1, pp. 77-92, 2018.

[29] N., Gamlo, "The Impact of Mobile Game-Based Language Learning Apps on EFL Learners' Motivation." English Language Teaching, vol.12, no.4, pp.49-56, 2019, doi: 10.5539/elt.v12n4p49.

[30] A., Bahari, "Game-based collaborative vocabulary learning in blended and distance L2 learning." Open Learning: The fournal of Open, Distance and e-Learning, vol. 35, no. 3, pp.34-59, 2020, 10.1080/02680513.2020.1814229.

[31] A. C. Fabregas, B. D. Gerardo, \& B. T. Tanguilig III, "Enhanced initial centroids for k-means algorithm," Int. F. of Information Technology and Computer Science," vol. 9, no. 1, pp.26-33, 2017, doi: 10.5815/ ijitcs.2017.01.04.

[32] J. Sandberg, M. Maris, \& K. De Geus, "Mobile English learning: An evidence-based study with fifth graders," Computers \& Education, vol.57, no. 1, 2011, pp. 1334-1347, doi: 10.1016/j.compedu.2011.01.015.

[33] E. Szewkis, M. Nussbaum, T. Rosen, J. Abalos, F. Denardin, D. Caballero, .... \& C. Alcoholado, "Collaboration within large groups in the classroom," International fournal of Computer-Supported Collaborative Learning, vol. 6, no. 4, pp. 561-575, doi: 2011, 10.1007/s11412-011-9123-y.

[34] I. S. Nation, Learning vocabulary in another language, Cambridge University Press, 2011.

[35] N. Schmitt, \& M. McCarthy, M., Vocabulary: Description, acquisition and pedagogy, Cambridge university press, 1997.

[36] S. Link, \& Z. Li, "Understanding online interaction through learning analytics: Defining a theory-based research agenda," in E. Dixon \& M.
Thomas (Eds.), Researching language learner interactions online: From social media to MOOCs, San Marcos, TX: CALICO Monograph Series, 2015, pp. 369-385.

[37] T. Gross, C. Stary, \& A. Totter, "User centered awareness in computer supported cooperative work systems: Structured embedding of findings from social sciences," International fournal of Human Computer Interaction, vol. 18, no.3, pp. 323-360, 2005 doi: 10.1207/s15327590ijhc1803_5

[38] S. Greenberg, C. Gutwin, \& A. Cockburn, "Awareness through fisheye views in relaxed WYSIWIS groupware" in Proceedings of Graphics interface, Toronto, Canada, 1996, pp.28-38.

[39] B. Mullen, \& G. R. Goethals, Theories of group behavior, New York, USA: Springer Science \& Business Media, 1987.

[40] A. Wigfield, \& J. T. Guthrie, "Relations of children's motivation for reading to the amount and breadth or their reading," fournal of educational psychology, vol. 89. No. 3, pp. 420, 1997, doi: 10.1037/0022-0663.89.3.420.

[41] C. H. Yu, "An introduction to computing and interpreting Cronbach Coefficient Alpha in SAS," in Proceedings of 26th SAS User Group International Conference,. Cary, NC: SAS Institute Inc, 2001 pp. 1-6.

[42] S. Ekiz, \& Z. Kulmetov, "The factors affecting learners' motivation in English language education," fournal of Foreign Language Education and Technology, vol. 1, no. 1, 2016.

[43] E. L. Snow, G. T. Jackson, L. K. Varner, \& D. S. McNamara, "The impact of system interactions on motivation and performance in a game-based learning environment," in International Conference on Human-Computer Interaction, Berlin, Germany, 2013, pp. 103-107.

[44] A. Tlili, F. Essalmi, \& M. Jemni, "Improving learning computer architecture through an educational mobile game." Smart Learning Environments, vol. 3, no. 1, 2016, pp. 7 .

[45] J. Sauro, "Best Practices For Using Statistics On Small Sample Sizes." Accesse: Feb. 07, 2020. [Online]. Available: https://measuringu.com/ small-n/

[46] B. A. Greene, R. B. Miller, H. M. Crowson, B. L. Duke, \& K. L. Akey, "Predicting high school students' cognitive engagement and achievement: Contributions of classroom perceptions and motivation," Contemporary Educational Psychology, vol. 29, pp. 462-482, 2004, doi: 10.1016/j.cedpsych.2004.01.006.

[47] H. W. Stevenson, C. Chen, \& S. Lee, "Motivation and achievement of gifted children in East Asia and the United States," fournal for the Education of the Gifted, vol. 16, pp. 223-250, 1993.

[48] A. I. Wang, "The wear out effect of a game-based student response system." Computers \& Education, vol. 82, pp. 217-227, 2015, doi: 10.1177/016235329301600302.

[49] P. Wouters, C. Van Nimwegen, H. Van Oostendorp, \& E. D. Van Der Spek, "A meta-analysis of the cognitive and motivational effects of serious games," Journal of educational psychology, vol. 105, no. 2, pp. 249, 2013, doi: $10.1037 / \mathrm{a} 0031311$.

[50] J. M. Keller, "Strategies for stimulating the motivation to learn," Performance+ Instruction, vol. 26, no. 8, pp. 1-7, 1987.

[51] E. Nuñez-Valdez, J. M. Cueva-Lovelle, C. P. G-Bustelo, G. InfanteHernandez, O. Sanjuan-Martinez, "Gade4all: developing multi-platform videogames based on domain specific languages and model driven engineering." International fournal of Interactive Multimedia And Artificial Intelligence, vol. 2. No. 2., pp. 33-42, 2013, doi: 10.9781/ijimai.2013.224.

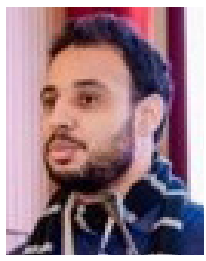

Ahmed Tlili

He is the Co-Director of the OER Lab at the Smart Learning Institute of Beijing Normal University (SLIBNU), China. He serves as the Associate Editor of the IEEE Bulletin of the Technical Committee on Learning Technology, and the Journal of e-Learning and Knowledge Society. He is also a Visiting Professor at UNIR-iTED, Spain, and an expert at the Arab League Educational, Cultural and Scientific Organization (ALECSO). Dr. Tlili has been awarded the IEEE TCLT Early Career Researcher Award in Learning Technologies for 2020. He is the CoChair of IEEE special interest group on "Artificial Intelligence and Smart Learning Environments" and APSCE's Special Interest Group on "Educational Gamification and Game-based Learning (EGG)". His research interests include, open education, game-based learning, educational psychology and artificial intelligence. 


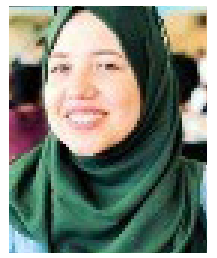

\section{Sarra Hattab}

She has a master degree in Intelligent information systems. Her research focuses on language learning using educational games.

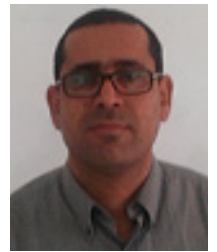

Fathi Essalmi

He is the former Head of the Computer Science Department at Kairouan University, Tunisia. He is currently an Assistant Professor at the University of Jeddah, Saudi Arabia. He supervises master's students and co-supervises Ph.D. students in two fields: learner modeling based on computer games and federation of personalization efforts. He has several publications with international team appeared in journals with impact factor and ranked conferences. He is also a program committee member in several conferences and a reviewer in several journals.

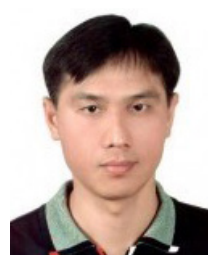

\section{Nian-Shing Chen}

He is currently Chair Professor in the Department of Applied Foreign Languages at the National Yunlin University of Science and Technology, Taiwan. He has published over 400 academic papers in the international referred journals, conferences and book chapters. One of his papers published in Innovations in Education and Teaching International was awarded as the top cited article in 2010. He is the author of three books with one textbook entitled "e-Learning Theory \& Practice”. He has received the national outstanding research awards for three times from the National Science Council in 2008, 2011-2013 and the Ministry of Science and Technology in 2015-2017.

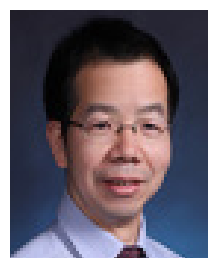

Ronghuai Huang

He is a Professor in Faculty of Education of Beijing Normal University (BNU). He has being engaged in the research on smart learning environment, artificial intelligence in education, educational technology as well as knowledge engineering. He received 'Chang Jiang Scholar' award in 2016, which is the highest academic award presented to an individual in higher education by the Ministry of Education of China. He serves as Co-Dean of Smart Learning Institute, Director of UNESCO International Rural Educational and Training Centre, and Director of China National Engineering Lab for Cyber learning Intelligent Technology. He is also the Editor-in-Chief of Springer's Journal of Smart Learning Environment and Journal of Computers in Education. Till now, he has finished over 100 projects, and published over 400 academic papers and 40 books.

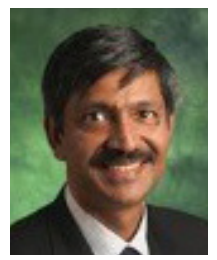

Kinshuk

He is currently a Professor of Computer Science and the Dean of the College of Information at the University of North Texas, USA. He received the Ph.D degree in computer science from the University of De Montfort, England, in 1996. He held the NSERC/CNRL/ Xerox/McGra Hil Research Chair for Adaptivity and Personalization in Informatics, funded by the Federal government of Canada, Provincial government of Alberta, and by national and international industries. Areas of his research interests include learning analytics; learning technologies; mobile, ubiquitous and location aware learning systems; cognitive profiling; and, interactive technologies.

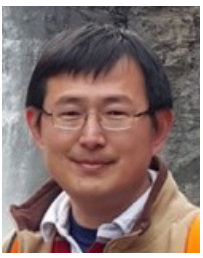

Maiga Chang

He is currently a Full Professor with the School of Computing Information and Systems, Athabasca University, Canada. He has given more than 105 talks and lectures in different conferences, universities, and events. He has participated in more than 310 international conferences and workshops as a Program Committee Member. He has (co-)authored more than 225 edited books, special issues, book chapters, journal and international conference papers. He is the Editor-in-Chief of the Educational Technology and Society, the Bulletin of Technical Committee on Learning Technology, and the International Journal of Distance Education Technologies. He was a Section Editor of the Education and Science, an Associate Editor of Transactions on Edutainment (Springer). He is an Advisory Board Member of the Journal of Computers and Applied Science Education. He is also the Chair of the IEEE Technical Committee of Learning Technology (IEEE TCLT), an Executive Committee Member of the Asia-Pacific Society for Computers in Education (APSCE), the Global Chinese Society for Computing in Education (GCSCE), and the Chinese Society for Inquiry Learning (CSIL). He is a Secretary and a Treasurer of the International Association of Smart Learning Environments (IASLE).

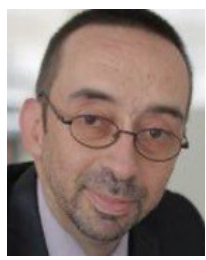

\section{Daniel Burgos}

He received a postgraduate in artificial intelligence \& machine learning from MIT, and the Ph.D. degree in communication, the Dr.Ing. degree in computer science, the Ph.D. degree in education, the Ph.D. degree in anthropology, and the D.B.A. degree in business administration. He is currently as a Full Professor of technologies for education \& communication and the ViceRector for International Research, the UNESCO Chair of eLearning, and the ICDE Chair of open educational resources with the Universidad Internacional de La Rioja. He is also the Director of the Research Institute for Innovation \& Technology in Education (UNIR iTED). He has published over 150 scientific articles, 20 books, and 15 special issues on indexed journals. He has developed +55 European and Worldwide Research and Development projects. His research interests include adaptive, personalised and informal eLearning, learning analytics, open education and open science, eGames, and eLearning specifications. 